\title{
Characterization of Enamel After the Use of Oral Hygiene Auxiliaries with Whiteners
}

\section{Caracterización del esmalte después del uso de auxiliares de higiene bucal con blanqueadores}

Zavala-Alonso Norma Verónica DDS, MSc, PhD1; Ramírez-González Jorge Humberto DDS, MSc; Ramírez-Vergara Mariana DDS²; Roque-Márquez José Gilberto DDS, MSc; Silva-Herzog Flores Daniel DDS, MSc, PhD¹

1. Doctorate Program in Dental Science, Faculty of Dentistry, Autonomous University of San Luis Potosí, San Luis Potosí, S.L.P, México.

2. Faculty of Dentistry, University of Veracruz, Veracruz, México.

Correspondence to: Dra. Norma Verónica Zavala-Alonso - nveroza@fest.uasIp.mx

Received: 14-V-2019

Accepted: 1-VII-2019

Published Online First: 8-VII-2019

DOI: $10.15517 / / J D S .2019 .38273$

\section{ABSTRACT}

The purpose of this study was to evaluate the effect of the use of the combined auxiliaries of oral hygiene with whitening agents on the micro-hardness and micro-morphology of dental enamel. Materials and Methods. 40 human incisors were used and sectioned to obtain $4 \times 4 \mathrm{~mm}$ samples and divided into four study groups. Group 1: Electric brushing with Toothpaste (BTP); Group 2: Electric brushing with Toothpaste+mouthwash (BTP+MW); Group 3: Electric brushing with Toothpaste+whitening pen (BTP+WP); Group 4: Electric brushing with Toothpaste+mouth wash+whitening pen (BTP+MW+WP). Samples were submitted toVickers micro-hardness test and visualized using scanning electron microscopy (SEM). Results. All groups, with the exception of group 1, showed a decrease in microhardness values after applying the treatments $(p<0.05)$. Likewise, when comparing the values after the treatments between the groups, significant statistical differences were found in all of comparisons except for those of groups 2 and 4. SEM images showed changes in the morphology in all the study groups with the exception of group 1. Conclusion. Significant changes such as decrease in micro-hardness as well as in the topography of the enamel surface such as elevations, craters, porosities and etching patterns were founded after the use of the combination of auxiliaries of oral hygiene with whitening agents.

\section{KEY WORDS}

Dental tissue; Oral hygiene; Bleaching teeth; Surface characterization; Vickers micro-hardness; Scanning electron microscopy. 


\section{RESUMEN}

El propósito de este estudio fue evaluar el efecto del uso de los auxiliares de higiene oral combinados con agentes blanqueadores sobre la microdureza y la micro-morfología del esmalte dental. Materiales y métodos. Se utilizaron 40 incisivos humanos y se seccionaron para obtener muestras de $4 \times 4 \mathrm{~mm}$ los cuales se dividieron en cuatro grupos de estudio. Grupo 1: cepillado eléctrico con pasta de dientes (BTP); Grupo 2: cepillado eléctrico con pasta dental+enjuague bucal (BTP+MW); Grupo 3: cepillado eléctrico con pasta dental+pluma blanqueadora (BTP+WP); Grupo 4: cepillado eléctrico con pasta dental+enjuague bucal+pluma blanqueadora (BTP+MW+WP). Las muestras fueron analizadas por medio de microdurezaVickers y microscopía electronica de barrido (SEM). Resultados. Todos Ios grupos, con la excepción del grupo 1, mostraron una disminución en los valores de microdureza después de aplicar los tratamientos $(p<0.05)$. Del mismo modo, al comparar los valores después de los tratamientos entre los grupos, se encontraron diferencias estadísticamente significativas en todas las comparaciones, excepto en las de los grupos 2 y 4 . Las imágenes de SEM nos muestran cambios en la morfología en todos los grupos de estudio con la excepción del grupo 1 Conclusión. Cambios significativos como la disminución de la microdureza y los cambios en la topografía de la superficie del esmalte, como elevaciones, cráteres, porosidades y patrones de grabado, se encontraron después del uso de la combinación de auxiliares de la higiene oral con agentes blanqueadores.

\section{PALABRAS CLAVE}

Tejido dental; Higiene oral; Blanqueamiento dental; Caracterización de superficies; Microdureza vickers; Microscopía electrónica de barrido.

\section{INTRODUCTION}

The today's cosmetic treatments are requested more and more by most of the patients looking for different methods to help them look younger, consequently dentistry does not escape to this current trend. One of the most solicited dental treatments now a day is teeth whitening. However, in many occasions the high costs these treatments represent or even the diverse technical impossibilities, make it impossible for the specialist to apply it to certain patients. Because of these situations, some turn to methods that are easier, more economical, and readily available like dental hygiene products that have a whitening effect. The market has, primarily, toothpastes, mouthwashes and whitening pen that can be named "Do-ityourself" products (DIY), which can contain different active ingredients such as carbamide peroxide, hydrogen peroxide (HP), or sodium bicarbonate.
The whitening substances are characterized by the bio-chemical reaction that causes the breaking off of pigmented molecules that have impregnated the dental structures, making them lighter. Consequently, they produce a significant reduction in the staining intensity, therefore the treatment whitens the teeth (1). Some authors have reported the adverse effects of using whitening agents as a loss of dental structure substance also irritation and peeling of the soft tissues $(1,2)$. However, this point remains controversial, considering the lack of consensus between the investigators. The addition of whitening agents in toothpaste formulations have been justified thanks to studies that have found that the loss of dental structure is probably caused by the act of brushing (that corrodes the surface and gives way to erosion) more than the whitening agents themselves $(3,4)$. The main factor associated with the degradation of the dental surface seems to do with how long 
the enamel is exposed to the whitening agent and not the concentration of the same $(3,5-7)$. Many studies have evaluated the effects of whiteners used at home and those applied in the dental office regarding the changes of the morphology and micro-hardness of the surface (8-13). Kwon et al. observed the effect of a DIY product on surface enamel and concluded that although the product does not induce adverse surface morphology changes when observed with SEM and can be considered safe, however, caution should be advised to the general public when using this type of products as it may adversely affect enamel microhardness (14). Previous studies have shown the effect on the enamel structure of oral hygiene products with or without bleaching agents within its composition $(7,14,15)$, however in our search of the literature we did not find any study that evaluated the effects on microhardness and morphological changes of the enamel surface of a multi-day dental cleaning regimen that includes the use of toothpaste, mouthwash and the use of whitening pen. The objective of this study was to evaluate the effects of the use of the combination of oral hygiene auxiliaries with whitening agents on the micro-hardness and micro-morphology of the dental enamel. The hypothesis set was that there would be difference in either of the variables (micro-hardness and micro-morphology of the dental surface), after using the combination of oral hygiene auxiliaries with whitening agents.

\section{MATERIALS AND METHODS}

\section{SUBJECTS AND PREPARATION FOR THE SAMPLE}

The patients that were going to have their upper or lower incisors removed due to periodontal disease in hospitals or private clinics in the city of Córdoba, Veracruz, México were asked to donate their dental organs once extracted and got signed consent from those who agreed. Autonomous University of San Luis Potosi Ethics Committee approved the research project grant CEIFE-020-018. All the obtained samples were cleaned and disinfected with a germicidal cleaner (BioSonic $®$ UC38, Colténe/Whaladent, Cuyahoga Falls, Ohio, USA) in an ultrasonic bath (Biosonic $®$ UC300-115B, Colténe/Whaladent, Cuyahoga Falls, Ohio, USA), they were later washed with running water, dried and analyzed by visual observation to discard any that did not meet the criteria for inclusion (no carious lesions or any type of pigmentation). The dental organs were stored in deionized water at $4^{\circ} \mathrm{C}$ until the experimental procedures took place. The oral surface of every dental organ was sectioned perpendicular to its axis by means of a diamond bur at low velocity and abundant irrigation (\#7910, medium grain; Brasseler, Savannah, GA, USA) in order to obtain the $4 \times 4 \mathrm{~mm}$ measurements, that were later mounted on acrylic blocks, followed by an ultrasonic bath of distilled water. 40 samples (according to the formula of Murray and Larry (16) of sample size for the infinite or unknown population) were obtained which were randomly divided into 4 study groups: Group 1: Electric brushing with Toothpaste (BTP); Group 2: Electric brushing with Toothpaste+mouthwash $(\mathrm{BTP}+\mathrm{MW})$; Group 3: Electric brushing with Toothpaste+whitening pen (BTP+WP); Group 4: Electric brushing with Toothpaste+mouth wash+whitening pen $(B T P+M W+W P)$.

METHOD APPLICATION METHOD OF ORAL HYGIENE AUXILIARIES WITH WHITENING AGENTS

Table 1 shows the hygiene auxiliaries used in the study. 
Table 1. Hygiene Auxiliaries used in the study.

\begin{tabular}{|c|c|c|}
\hline Type & Commercial brand & Composition and pH \\
\hline Anti-caries toothpaste & Luminous White- Colgate & $\begin{array}{l}\text { 0.243\% Sodium Fluoride (1100 ppm), Water, sorbitol, } \\
\text { Hydrated silica, PEG-12, Sodium Lauryl Sulfate,Cellulose } \\
\text { gum,Potassium Hydroxide, Tetrasodium Pyrophosphate, } \\
\text { Phosporic Acid,Cocamidopropyl Betaine,Benzyl } \\
\text { Alcohol,Sodium saccharin,Cl 77891, pH 7.0 }\end{array}$ \\
\hline Mouth Wash & Luminous White- Colgate & $\begin{array}{l}\text { Water, sorbitol, } 2 \% \text { Hydrogen Peroxide, poloxamer } 338 \text {, } \\
\text { polysorbate } 20 \text {, methyl silicate, menthol, sodium saccharin } \\
\text { pH } 4.0\end{array}$ \\
\hline Mouth Wash & Luminous White- Colgate & $\begin{array}{l}\text { Water, sorbitol, } 2 \% \text { Hydrogen Peroxide, poloxamer } 338 \text {, } \\
\text { polysorbate } 20 \text {, methyl silicate, menthol, sodium saccharin, } \\
\text { pH } 4.0\end{array}$ \\
\hline Whitening pen (Dental Gel) & Luminous White- Colgate & $\begin{array}{l}4.5 \% \text { Hydrogen peroxide at } 4.5 \% \text {, Dimethicone, Paraffinum } \\
\text { liquidum, Trimethylsiloxysilicate, Polyethylene, sodium } \\
\text { saccharin, Eugenol, } \mathrm{pH} 6.0\end{array}$ \\
\hline Artificial saliva & Viarden & $\begin{array}{l}\text { Sodium, potassium, calcium, magnesium, fluorine, chlorine } \\
\text { and phosphate }\end{array}$ \\
\hline
\end{tabular}

\section{METHOD OF DENTAL BRUSHING}

All study groups received this technique. A schedule was established which represented the 3 normally recommended times for brushing, these being; 8:00, 11:30 and 15:00hrs, then placing the samples in an incubator in artificial saliva (Viarden, México) at 370C between each time period. A solution of toothpaste was prepared in a $1: 3$ ratio $(10 \mathrm{ml}$ of toothpaste dissolved in $20 \mathrm{ml}$ of distilled water), which was placed on the surface of the sample. An electric brush (Pro-Salud,Oral B, Procter \& Gamble Co., Cincinnati, OH, USA) with soft nylon bristles and polished, rounded tips spinning at 150rmp was placed and fixed firmly with the help of dental acrylic on a dynamometer at an angulation of $90^{\circ}$ under constant pressure of $2 \mathrm{~N}$ for 2 minutes. When brushing treatments were completed, the specimens were washed out with distilled water and stored once again in artificial saliva in the incubator at $37^{\circ} \mathrm{C}$. This cleaning regime was done during a period of 10 days for every sample.

\section{METHOD OF MOUTH WASHING}

The samples of the groups that received this hygienic auxiliary were previously brushed under the previously describes regime, then were submerged in $30 \mathrm{ml}$ of mouthwash solution and subjected to agitation for 60 seconds on an agitator platform (Cientec CT 158) simulating a mouth rinsed, and rinsed with distilled water after the procedure and immersed in $5 \mathrm{ml}$ of artificial saliva and taken to the incubator at $370 \mathrm{C}$ for their storage.

\section{METHOD OF WHITENING BUSHING}

The dental gel contained in the whitening pen was applied on the surface of the sample 
for 5 seconds using circular movements. After the treatment, the samples were not rinsed, but just immersed in artificial saliva and taken to the incubator at 370C for their storage.

\section{MICRO-HARDNESS TEST}

Vickers HV-1000 for micro-hardness (DongGuan Sinowon Precision Instrument Co., Ltd. South District DongGuan, China), was used charged at $50 \mathrm{gf}$ and a penetration time of 15 seconds. All of the samples were evaluated in triplicate before and after the materials were applied, according to their study group.

The Vickers Microhardeness tester (HVS1000Z, Sinowon, DongGuan, CHN) was used to determine the Vickers microhardness. The indentations were performed in two stages: before and after treatments. Three indentations were performed with a load of $50 \mathrm{Kg}$ for 30 seconds.

\section{EVALUATION FOR SCANNING ELECTRON MICROSCOPY (SEM)}

Representative sample of each study group were used before and after the materials were applied for the analysis. For their preparation, each sample was immersed in ascending concentrations of ethanol $(50 \%, 70 \%$ y $90 \%)$ for 20 min each and at the $100 \%$ for one hour. Afterwards they were covered by a thin coat of gold (S150A sputter coater, Edwards; London, UK). The samples were then observed using a SEM (JSM-6510, JEOL, Tokyo, JAP) at $5 \mathrm{KV}$ and y examined at 1000x and at a scale of $10 \mu \mathrm{m}$.

\section{STATISTICAL ANALYSIS}

All data were expressed as a mean \pm standard deviation. Shapiro Wilks and Brown Forsythe tests were used to assess the normality of the data distribution. Two-way ANOVA factorial analysis was used to compare VHN values at baseline and 10 days after treatment among the all experimental groups. The Student $t$ test was used to find significant differences between the means when ANOVA result was significant. All statistic analyses were conducted using the StatView1 5.01 software (SAS Institute, Cary, NC). The difference between groups was considered statistically significant at an $p<0.05$.

\section{RESULTS}

\section{VICKERS MICRO-HARDNESS}

Table 2 shows us the mean and standard deviations of the Vickers hardness number (VHN) in the study groups in its baseline state and 10 days after the treatment. There was no statistically significant difference in the VHN in its baseline state among the experimental groups (Two-way analysis, $p>0.05)$. It can be observed that in all of the study groups the VHN decreases after 10 days of treatment in comparison to its baseline state, with statistically significant difference (Two-way analysis, $p<0.05)$. When comparing these values (before and after the treatment), significant statistical differences (student $t$ test, $p<0.05$ ) were observed in all the groups except for group 1. Likewise, we observed that the lowest percentage $(-10 \%)$ of the decrease in the micro-hardness of the enamel after the treatment was found in group 1 and the highest percentage (36\%) was found in group 4. There was statistically significant difference in the VHN observed 10 days after treatment among the experimental groups (Two-way analysis, $p>0.05)$. When comparing pairs of groups, significant statistical differences was founded in all the comparisons with exception of groups 2 vs 4 (student t test, $p<0.05$ ); the most evident difference was found in groups 1 vs 2 and 1 vs 4 . 
Table 2. Statistical description and comparison of the Vickers hardness number VHN in the different study groups in its baseline state and after 10 days of treatment.

\begin{tabular}{ccc}
\hline Group & Baseline & $\mathbf{1 0}$ days \\
\hline & \multicolumn{2}{c}{ VHN Mean \pm DE $(\% \mathrm{D})$} \\
\cline { 2 - 3 } 1) BTP & $422.32 \pm 56.56 \mathrm{a}$ & $382.99 \pm 110.30(-10 \%) \mathrm{a}$ \\
2) BTP + MW & $411.08 \pm 113.96 \mathrm{a}$ & $264.23 \pm 59.48(-35 \%) \mathrm{bc}$ \\
3) BTP + WP & $416.04 \pm 94.84 \mathrm{a}$ & $306.16 \pm 60.78(-27 \%) \mathrm{bd}$ \\
4) BTP + MW + WP & $418.15 \pm 111.48 \mathrm{a}$ & $269.13 \pm 74.33(-36 \%) \mathrm{bc}$ \\
\hline
\end{tabular}

$\mathrm{VHN}=$ Vickers hardness number; $\mathrm{DE}=$ Standard Deviation; $\% \mathrm{D}=$ percentage of decrease with reference to baseline; $\mathrm{BTP}=\mathrm{Electric}$ Brushing with toothpaste; MW= Mouth Wash; WP= Whitening Pen. Different letters in the same column or the same row denote statistically significant differences $(p<0.05)$.

\section{SCANNING ELECTRON MICROSCOPY (SEM)}

Figure 1 shows us representative images of the SEM of the micromorphology of the enamel surface before the treatment (baseline state) and 10 days after being treated according to the study group specifications. It can be observed that the morphology of the surface of the enamel previous to the different treatments is typical to the prismatic enamel, that is to say, with an irregular geology with elevation, craters and fractures (Fig.1a). The surface of the enamel after the 10 days of brushing with whitening toothpaste shows great similarities to the baseline state, with lines present along the surface probably caused by the mechanical function of the toothbrush (Fig.1b). The surface of the enamel of the group where, besides brushing with toothpaste, mouth wash was added daily for 10 days shows morphological characteristics of a prismatic enamel (presence of prisms of the enamel) with pores and irregular elevations (Fig.1c). The enamel's surface of the group where, besides brushing with toothpaste, a whitening pen was used, shows characteristics of prismatic enamel with evidence of an etching pattern type I (nucleus of the prism) in some areas of the sample (Fig.1d). The enamel's surface of the group where, besides brushing with toothpaste, mouth wash and whitening pen were used, also show characteristics of prismatic enamel, with high reliefs, presence of transversal and longitudinally cut adamantine prisms, as well as areas with engraved patterns type I (Fig.1e). 

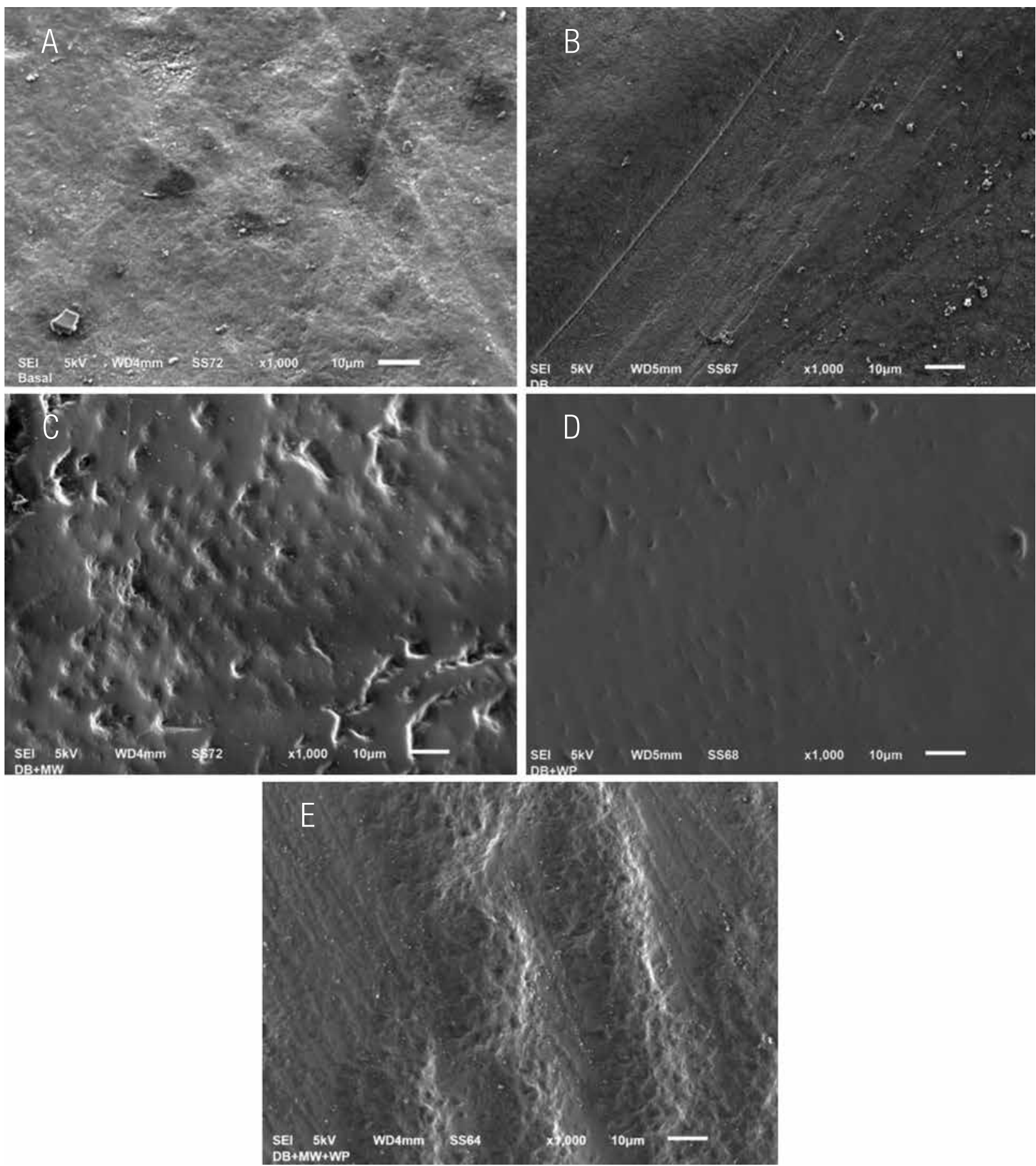

Figure 1. Images of the Electronic Microscopy at 1,000x of the enamel surface of the different study groups a) Enamel surface in Baseline state (before the treatment); b) Enamel surface of group 1 (Electric brushing with Toothpaste) after 10 days treatment; c) Enamel surface of group of group 2 (Electric brushing with Toothpaste+mouthwash) after 10 days treatment; d) Enamel surface of group 3 (Electric brushing with Toothpaste+whitening pen) after 10 days treatment; e) Enamel surface of group 4 (Electric brushing with Toothpaste+mouth wash+whitening pen) after 10 days treatment. 


\section{DISCUSSION}

The present study evaluated the changes in the micro-hardness and the micro-morphology of the enamel's surface after the use of different combinations of oral hygiene auxiliaries with whitening effects. Peters in 2010 and Kwon in 2015 stated that the interface of the dental surface exhibits continuous and dynamic ionic changes between the oral biofilm and the apatite crystals in both directions to maintain an adequate mineral balance, which makes it difficult to interpret the clinical relevance of the results obtained in microhardness and enamel morphology tests (1314). Despite this and the limitations of this study in vitro, both the micro-hardness and the micromorphology of the enamel surface was found to decrease after 10 days of applying any oral hygiene auxiliaries and/or a combination of them, accepting the proposed hypothesis. Significant statistical differences were found in the micro-hardness of almost all the different combinations of the oral hygiene auxiliaries with whitening effect, except between the groups that combined the use of dental brushing and mouth wash and the group that combined the use of dental brushing, mouth wash and whitening pen; the absence of difference is due to that both groups had the highest and most similar percentages in the decrease on microhardness (35 and 36\% respectively). We observe that both groups include the use of mouth wash and that its use just with the toothbrush is enough to have a significant decrease in the micro-hardness and that adding the whitening pen, even though it increases the percentage of decrease, had no significant results. The results of the present study agree with those found by Fernandes et al., When finding a decrease in the microhardness of the enamel surface after the use of a mouth rinse with $1.5 \%$ hydrogen peroxide content and a pH of 3.8 . It can be assumed that the low pH of the whitening mouthwash (which is not present in the toothpaste or in the content of the whitening pen) may have acted on the demineralization of enamel surface favoring the decrease of microhardness, since the $\mathrm{pH}$ value is less than the enamel critical pH (5.5) (15).

Searching in literature, we didn't find studies that evaluate the effects on the surface of the enamel after the use of certain whitening pens, however our results were comparable to a study found where the evaluation of the micro-hardness of the surface of the enamel after the use of whitening strips that also contain HP as the active agent, although it had a higher percentage $(9.5 \%)$ than what was reported in the whitening gel pens (4.5\%). When comparing our results with the previously mentions study, we found that they don't coincide, since they do not report statistically significant differences when comparing the micro-hardness before a treatment (baseline) with the later results, the explanation may be due to various factors among the mentioned: the physical and technical consistency of the applied materials, since the gel from the whitening pen is applied in greater quantities and the application of mechanics to rub it on the enamel, an activity that does not apply when using strips. Even though strips have more $\mathrm{HP}$, the quantity of the compound that comes in contact with the enamel's surface is much less than with the gel (14). The electronic microscopy has been widely used in the analysis of the morphology of the enamel's surface after the use of dental whitening techniques. The reported results have varied depending on design of the study, type and concentration of $\mathrm{HP}, \mathrm{pH}$, and time exposed, which could have no change on the morphology of the surface $[12,18)$ up to mild alterations of porosity in the surface (8-9). One recent study that compared HP neutral and acidity in the morphology of the surface showed the neutral HP did not affect the morphology of the surface, while the acid HP had significant changes on the enamel's surface (19). Therefore, it is suggested that the studies that use whitening agents with relatively low PH probably describe the demineralization caused by acid erosion process more than the adverse effects of peroxide per se (20-21). Based on our SEM 
results, it can be observed, with the exception of the group that only used brushing with toothpaste and whitening pen, that all the groups in the study suffered modifications in the enamel's surface (accepting therefore the hypothesis of our second variable); interestingly these same groups suffered significant decrease in the Vickers hardness, showing loss in the mineral of the enamel as well as visible changes in the morphology of the surface. A possible explanation for this phenomenon is that the whitening process is produced by the oxidation of the pigments that are found in the dental enamel by the chemical products that are found in the whitening agents (22). In our search for literature, no articles were found that evaluate the effects that the oral hygiene auxiliaries and the whitening effects have on the micro-hardness and surface of the dental enamel. Follow up studies in vitro e in vivo needs to be made, to evaluate more adverse effects that commercial products can have on the surface of the enamel.

\section{CONCLUSION}

Dental brushing using toothpaste with whitening effects does not produce significant changes in the enamel's surface, but the combination with other oral hygiene auxiliaries that contain HP in different concentrations like that of mouth washes and whitening pens can cause important changes in the micro-hardness and the morphology of the enamel's surface.

\section{ACKNOWLEDGMENTS}

This work was partially supported by Consejo Nacional de Ciencia y Tecnología (CONACYT; Grant No.178261).

\section{REFERENCES}

1. Kawamoto K., Tsujimoto Y. Effects of the Hydroxyl Radical and Hydrogen Peroxide on Tooth Bleaching. J Endod 2004; 30 (1): 45-50.
2. Sulieman M., Addy M., Macdonald E., Rees J. A safety study in vitro for the effects of an in-office bleaching system on the integrity of enamel and dentine. J Dent 2004; 32 (7): 581-590.

3. Worschech C.C., Rodrigues J.A., Martins L.R., Ambrosano G.M. In vitro evaluation of human dental enamel surface roughness bleached with $35 \%$ carbamide peroxide and submitted to abrasive dentifrice brushing. Braz Oral Res 2003; 17: 342-348.

4. Ren Y. F., Amin A., Malmstrom H. Effects of tooth whitening and orange juice on surface properties of dental enamel. J Dent 2009; 37 (6): 424-431.

5. Wiegand A., Otto Y. A., Attin T. In vitro evaluation of toothbrushing abrasion of differently bleached bovine enamel. Am J Dent 2004; 17 (6): 412-416.

6. Pinto C. F., Giannini M., Cavalli V., Oliveira, R. Peroxide bleaching agent effects on enamel surface microhardness, roughness and morphology. Braz Oral Res 2004; 18 (4): 306-311.

7. de Araújo D., Campos E., Silva L., Correia de Araújo R. In vitro study on tooth enamel lesions related to whitening dentifrice. Indian Journal of Dental Research 2011; 22 (6): 770-776.

8. Ben-Amar A., Liberman R., Gorfil C., Bernstein Y. Effect of mouthguard whitening on enamel surface. Am J Dent. 1995; 24: 817-824.

9. Yeh S.T., Su Y., Lu Y.C., Lee S.Y. Surface changes and acid dissolution of enamel after carbamide peroxide bleach treatment. Oper Dent. 2005; 30 (4): 507-15.

10. Potoc`nik I., Kosec L., Gas`pers ^ic` D. Effect of $10 \%$ carbamide peroxide whitening gel on enamel microhardness, microstructure, and mineral content. J Endod. 2000; 26: 203-6.

11. Basting R.T., Rodrigues A.L., Serra M.C. The effect of $10 \%$ carbamide peroxide, carbopol and/ or glycerin on enamel and dentin microhardness. Oper Dent. 2005; 30 (5): 608-616. 
12. Scherer W., Penugonda B., Styner D., Georgescu M. At-home vital bleaching: effects on stained enamel and dentin. Pract Periodontics Aesthet Dent. 1992; 4 (2): 11-15.

13. Peters M. C. Strategies for noninvasive demineralized tissue repair. Dent Clin N Am. 2010; 54 (3): 507-25.

14. Kwon So, Kurti Steven, Oyoyo Udochukwu, Li Yiming. Effect of various tooth whitening modalities on microhardness, surface roughness and surface morphology of the enamel. Odontology 2015; 103 (3): 274-279.

15. Fernandes F. P., Pedroso-Turssi C., Mantovani F., Tarkany-Basting R., LucisanoBotelho do Amaral F. Whitening mouthwash containing hydrogen peroxide decreases enamel microhardness in vitro. Brazilian Journal of Oral Sciences 2017; 16: 1-9.

16. Murray R. Spiegel y Larry J. Stephens. (2009). Estadística. 4ta edición. Mc GrawHill. México, D.F.

17. Karadas M., Hatipoglu O. Efficacy of Mouthwashes Containing Hydrogen Peroxide on Tooth Whitening. Scientific World Journal. 2015; 2015: 961403.
18. Götz H., Duschner H., White D. J., Klukowska M. A. Effects of elevated hydrogen peroxide 'strip' whitening on surface and subsurface enamelincluding subsurfacehistomorphology, micro-chemical composition andfluorescence changes. J Dent. 2007; 3586): 457-466.

19. Sun L., Liang S., Wang Y. S. Z., Jiang T., Wang Y. Surface alteration of human tooth enamel subjected to acidic and neutral 30\% hydrogen peroxide. J Dent. 2011; 39 (10): 686-692.

20. Joiner A. Review of the effects of peroxide on enamel and dentine properties. J Dent. 2007; 35 (12): 889-896.

21. Worschech C. C., Rodrigues J. A., Martins L. R., Ambrosano G. M. Brushing effect of abrasive dentifrices during at-home bleaching with $10 \%$ carbamide peroxide on enamel surface roughness. J Contemp Dent Pract 2006; 7 (1): 25-34.

22. Navimipour E. J., Kimyai S., Nikazar S., Ghojazadeh M. In vitro evaluation of the effect of delaying toothbrushing with toothpaste on enamel microhardness subsequent to bleaching the teeth with $15 \%$ carbamide peroxide. Oper Dent 2012; 37 (1): 87-92. 